\section{New murmurs in patients with prosthetic heart valves}

\section{N A Cromie, S J Walsh, A A M Ahmed, G Campalani}

Answers on $p 480$.

\section{CASE 1}

A 58 year old woman with previous replacement of a bicuspid aortic valve (size 23 St Jude Medical prosthesis) in 1994 for aortic stenosis, presented with a three week history of increasing shortness of breath. During this time she had stopped her diuretic as she had suffered an acute exacerbation of gout. On initial assessment, an ejection systolic murmur and early diastolic murmur were noted. The patient was found to be in moderate left heart failure (Killip class II). Echocardiography demonstrated a peak systolic velocity of $4.7 \mathrm{~m} / \mathrm{sec}$ across the aortic valve (peak gradient of $85 \mathrm{~mm}$ $\mathrm{Hg}$ ). There was moderate aortic regurgitation and it appeared that the prosthesis was malfunctioning. There was no evidence of endocarditis and the patient's international normalised ratio was
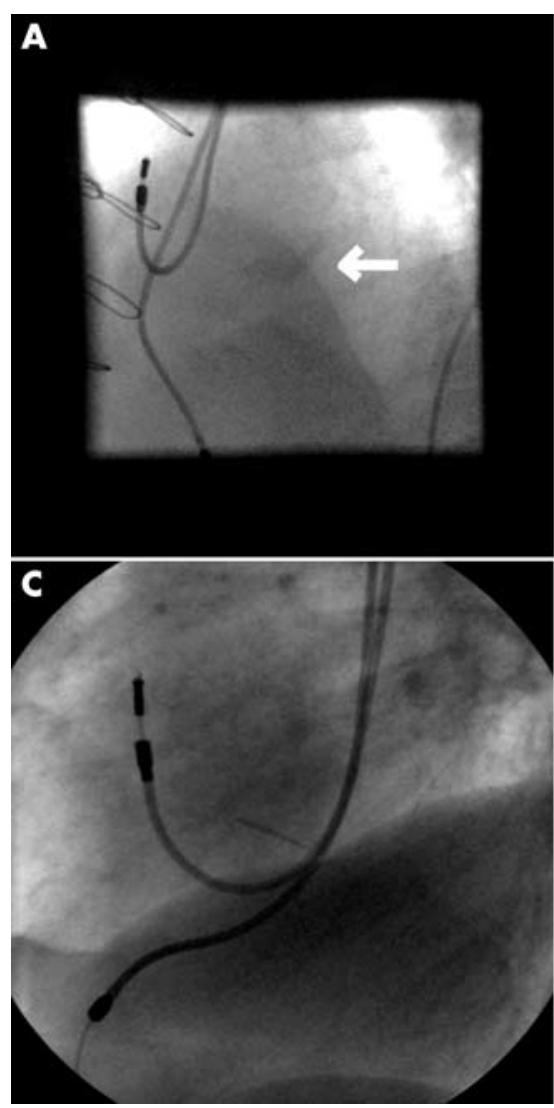

Figure 1 Valve screening. (A) Left anterior oblique view in diastole; (B) left anterior oblique view in systole; (C) left lateral view in diastole; (D) left lateral view in systole.
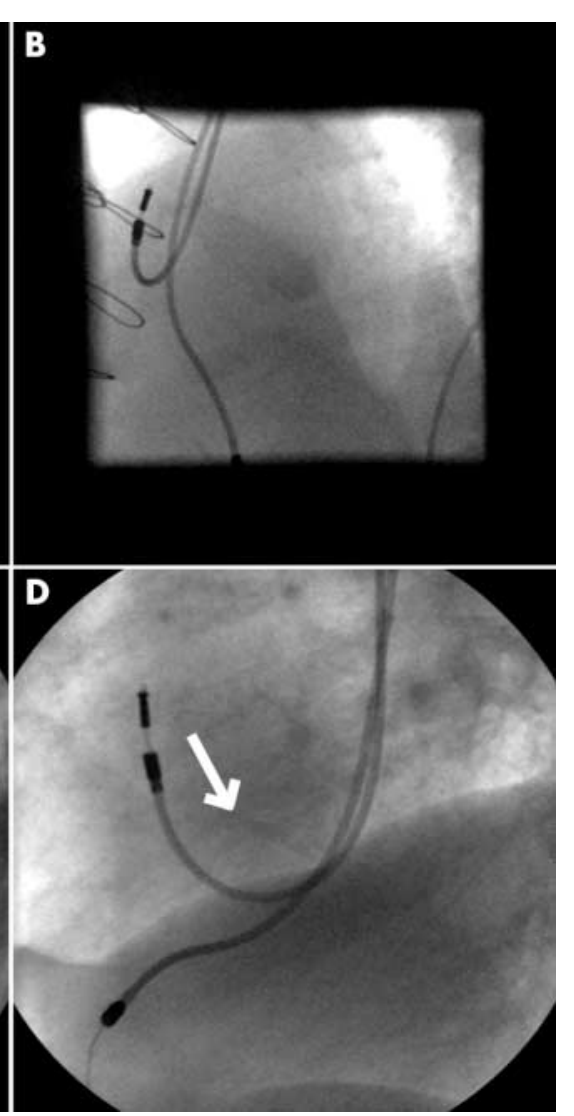

therapeutic at 2.1. Radiographic valve screening was performed and the appearances are demonstrated in fig 1 .

\section{CASE 2}

A 19 year old woman had undergone tricuspid valve replacement for staphylococcal endocarditis (there was no evidence of intravenous drug abuse) in October 1998. A size 29 St Jude Medical prosthesis was implanted. During routine follow up in February 2001, a transthoracic echocardiogram was performed. It showed that the tricuspid valve prosthesis was "functioning satisfactorily". By March 2001 the patient started to develop signs of tricuspid regurgitation. A pansystolic murmur was noted at the lower left sternal edge and this was associated with giant $\mathrm{CV}$ waves. There was no overt right heart failure. A transoesophageal echocardiogram was performed. This demonstrated that the tricuspid valve was malfunctioning and mild to moderate tricuspid regurgitation was noted. The patient's C-reactive protein was normal $(<7 \mathrm{mg} / \mathrm{l})$, as were the white blood cell count and erythrocyte sedimentation rate. The patient was apyrexial and had no clinical evidence of infective endocarditis. The international normalised ratio was 2.5 . The valve was eventually excised and the appearances of the valve are shown in fig 2 .

\section{QUESTIONS}

(1) What is the differential diagnosis to explain the presentation of these patients.

(2) What pathological mechanisms are possible causes of prosthetic valve obstruction and what has happened in case 2?

(3) What is the most helpful investigation to differentiate these pathological mechanisms?

(4) What are the therapeutic options for patients with prosthetic valve obstruction?

Postgrad Med J 2003;79:476

\section{Authors' affiliations}

N A Cromie, S J Walsh, Regional Medical Cardiology Centre, Royal Victoria Hospital, Belfast, Northern Ireland

A A M Ahmed, G Campalani, Department of Cardiac Surgery, Royal Victoria Hospital,

Belfast, Northern Ireland

Correspondence to: Dr Nicholas A Cromie, Royal Victoria Hospital, Belfast BT12 6BA, UK; cardiac.research@royalhospitals.n-i.nhs.uk

Submitted 11 November 2002

Accepted 31 December 2002

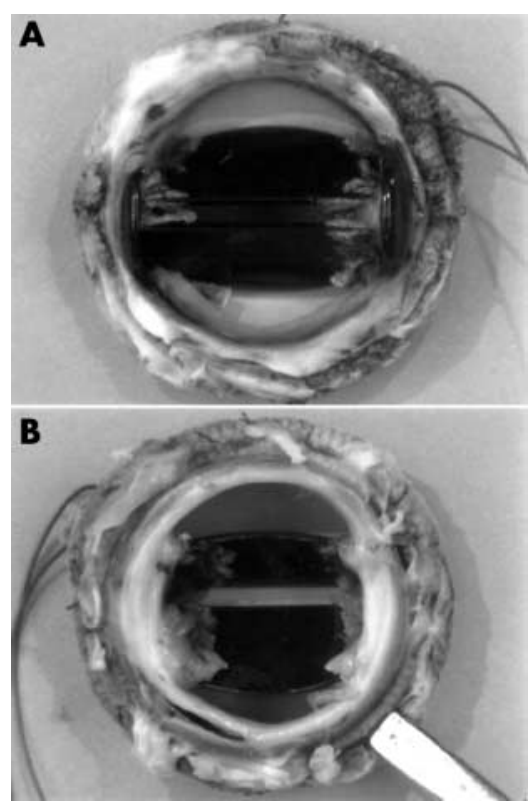

Figure 2 Prosthetic valve pathology. (A) Tricuspid valve prosthesis inflow; (B) tricuspid valve prosthesis oufflow. 


\section{An unusual cause of peripheral neuropathy in a diabetic patient on dialysis: "a sural surprise"}

\section{A Slack, D J A Goldsmith}

\section{Answers on p 480.}

$\mathrm{P}$ ripheral neuropathy is a common medical problem, with many potential aetiologies. ${ }^{\prime}$ One of the commonest systemic diseases to cause a peripheral neuropathy is diabetes mellitus. ${ }^{2}$ Patients with end stage renal failure are also prone to develop peripheral neuropathy, in part related to how well uraemic toxins are removed by renal replacement therapy. ${ }^{4}$

We present the case of a woman with diabetes, on dialysis treatment, who developed an acute severe peripheral neuropathy. There were unusual clinical and investigational findings that mandated further diagnostic work-up.

\section{CASE REPORT}

An overweight woman, born in Antigua in 1948, developed type II diabetes mellitus in 1979. From 1983 she required oral hypoglycaemic agents then insulin. In 1994 she developed heavy proteinuria and impaired renal function (inulin glomerular filtration rate $52 \mathrm{ml} / \mathrm{min}$ corrected for body surface area, $n=125$ $\mathrm{ml} / \mathrm{min} / 1.73 \mathrm{~m}^{2}$ ) and required retinal laser photocoagulation.

She was lost to follow up, but reappeared in 1998 no longer on insulin but metformin with a plasma creatinine of $250 \mu \mathrm{mol} / \mathrm{l}$ (normal range 52-116), a creatinine clearance of $25 \mathrm{ml} / \mathrm{min}, 11.8 \mathrm{~g}$ of urinary protein excretion per 24 hours, and a glycated haemoglobin (HbAlc) of 8.8\%. By February 1999 she required renal replacement therapy by means of chronic ambulatory peritoneal dialysis. An adequacy test, soon after starting therapy, indicated she was well dialysed. In addition, there was some degree of improved glycaemic control back on insulin with a HbAlc of $8.1 \%$. By May 2001 she was having major problems, with several weeks of a hoarse voice, a nodular itchy skin eruption, with profound distal muscle weakness and numbness, and an unsteady gait. On admission she was found to have severe distal muscle weakness, wasting, dysmetria and ataxia, and marked acral reduction in pinprick, pain, and vibrationsense. Deep tendon reflexes were absent. A chest radiograph showed bilateral hilar lymphadenopathy. Computed tomography of the chest showed normal lung parenchyma, but right paratracheal and bilateral mediastinal lymphadenopathy (see fig 1 ).

Flexible narendoscopy showed the right arytenoids overriding with right vocal cord paralysis. This is likely to have been secondary to compression of the right recurrent laryngeal nerve from the paratracheal lymph nodes. Laboratory
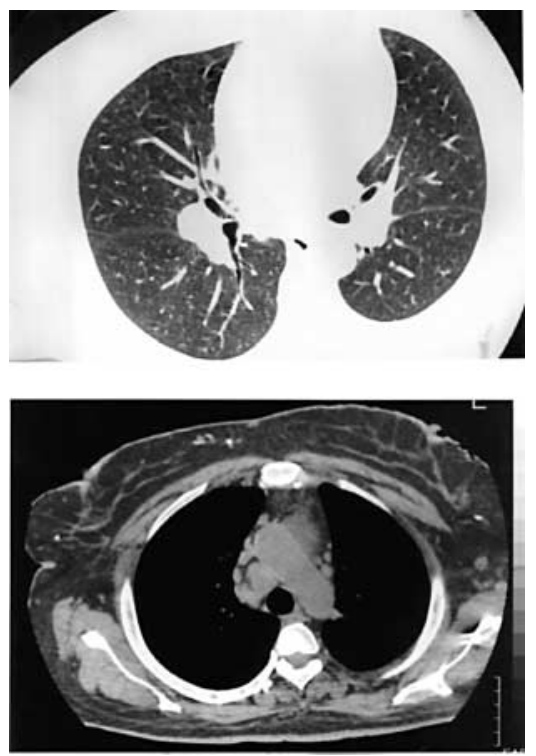

Figure 1 Computed tomography of chest. investigations revealed raised plasma calcium $3.11 \mathrm{mmol} / \mathrm{l}$ (2.2-2.6), suppressed parathyroid hormone $5 \mathrm{nmol} / \mathrm{l}$ $(10-65)$, raised total globulins at $46 \mathrm{~g} / \mathrm{l}$ (20-35), raised IgG $24.6 \mathrm{~g} / \mathrm{l}(5-18)$ with a polyclonal pattern on electrophoresis, and abnormal liver function tests alkaline phosphatase $375 \mathrm{IU} / \mathrm{l}(50-120)$ and $\gamma$-glutamyltransferase 113 IU/l (26-52). C-reactive protein was $16 \mathrm{mg} / \mathrm{l}(<5)$.

A comprehensive autoantibody screen was negative. A nerve conduction study showed a demyelinating symmetrical sensory motor polyneuropathy. The degree of slowing and the presence of partial conduction block in the ulnar nerve at the forearms were not consistent with diabetic or uraemic neuropathies.

This impressive collection of abnormal test results (hypercalcaemia; lymphadenopathy; polyclonal IgG increase; abnormalities of liver function; and the severity and type of motor sensory peripheral neuropathy) required two additional investigations to be performed, unifying the diagnosis.

\section{QUESTIONS}

(1) What were these two diagnostic procedures?

(2) What is the underlying diagnosis?

(3) What treatment is there, and what is the prognosis?

Postgrad Med J 2003;79:477

\section{Authors' affiliations}

A Slack, D J A Goldsmith, Department of Renal Medicine, Guy's Hospital, Guy's, King's and St Thomas' Medical School, London

Correspondence to: Dr David Goldsmith, Renal Unit, Guy's Hospital, London SEI 9RT, UK; david.goldsmith@gstt.sthames.nhs.uk

Submitted 23 September 2002

Accepted 3 December 2002

\section{References}

1 Poncelet AN. An algorithm for the evaluation of peripheral neuropathy. Am Fam Physician 15 February 1998 (http://www.aafp.org/ afp/980215ap/poncelet.html).

2 Charles M, Clark D, Lee A. Prevention and Charles M, Clark D, Lee A. Prevention and
treatment of the complications of diabetes mellitus. N Engl J Med 1995;332:1210-17.

3 Partanen J, Niskanen L, Lehtinen J, et al. Natural history of peripheral neuropathy in patients with non-insulin diabetes mellitus. $N$ Engl J Med 1995;333:89-94.

4 Bolton CF, Young GB. Uraemic neuropathy. Neurological complications of renal disease. London: Butterworth-Heinemann, 1990. 
Uncommon cause of hepatosplenomegaly in an immunocompetent patient

\section{A Mohan, R Guleria, J C Samantaray, A Kumar Dutta, S Tandon, J N Pande}

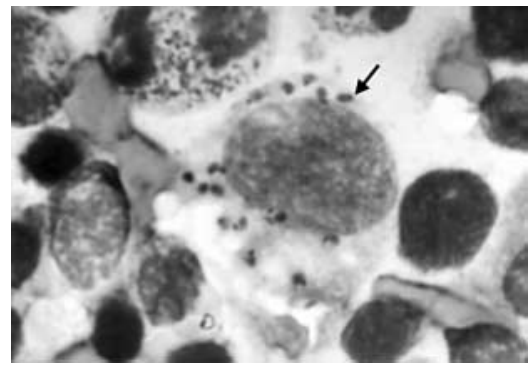

Figure 1 Bone marrow (Giemsa stain $x$ 1500).

\section{QUESTIONS}

(1) What does the bone marrow show?

(2) What is the diagnosis and what further corroborative tests may be done? (3) What is atypical in this patient's presentation?

(4) How is this condition treated?

Postgrad Med J 2003;79:478 with reversal of albumin-globulin ratio ( $24 \mathrm{~g} / \mathrm{l}$ and $62 \mathrm{~g} / \mathrm{l}$ respectively). His renal profile, serum bilirubin, and aminotranferase levels was normal. Peripheral smear was negative for malarial parasite and did not show any abnormal cells. Abdominal ultrasound revealed massive splenomegaly $(28 \mathrm{~cm})$ and mild hepatomegaly with normal portal vein and splenic vein diameters. Echocardiography did not show any vegetations. IgG enzyme linked immunosorbent assay (ELISA) for HIV was negative. Blood levels of IgG, IgM, and IgA were also normal. At this stage a bone marrow examination was done (fig 1).

\section{A conundrum from antenatal testing}

\section{Cameron, G Cumming, P Smith}

\section{Answers on p 482.}

A 30 year old primigravida booked into the department of obstetrics and gynaecology at 13 weeks by her last menstrual period. There was no medical history of note. Booking abdominal ultrasound scan revealed a singleton pregnancy with a crown rump length corresponding to a gestation of 10 weeks and 4 days. This discrepancy in "dates" was attributed to her conceiving within a cycle of stopping the combined oral contraceptive pill.

Biochemical screening for Down's syndrome and open neural tube defect (NTD) was performed at 16 weeks. Her risk for an open NTD was reported as low ( 0.7 multiple of the median) and her risk for trisomy 21 had decreased from an age related risk of $1: 796$ to a biochemical determined risk of 1:5000.

At 20 weeks she attended for her routine fetal anomaly scan. The fetus was found to have mild bilateral cerebral ventriculomegaly of $11 \mathrm{~mm}$ and a reduced abdominal circumference equivalent to that of a 17 week fetus. The rest of the measurements were appropriate for a fetus of 20 weeks and no other fetal or placental abnormalities were found.

\section{Authors' affiliations}

A Mohan, R Guleria, J C Samantaray,

A Kumar Dutta, S Tandon, J N Pande, All India Institute of Medical Sciences, New Delhi, India

Correspondence to: Dr Randeep Guleria, Department of Medicine, All India Institute of Medical Sciences, New Delhi, 110029 , India; randeepg@hotmail.com

Submitted 26 October 2002

Accepted 20 January 2003

She was therefore referred to the regional maternal-fetal medicine tertiary centre for further assessment. The ultrasound findings were confirmed and after counselling she underwent amniocentesis and the sample (a non-“bloody tap") sent for karyotyping and fluorescent in situ hybridisation (FISH).

The FISH analysis reported that in $50 \%$ of the cell lines there was trisomy of chromosomes 13, 18, and 21. The other $50 \%$ of cell lines were reported as showing a diploid chromosomal complement. The karyotype of the cells grown from culture of the amniotic fluid showed a chromosomal complement of $69, \mathrm{XXX}$ in $50 \%$ of the cell lines and a 46,XX complement in the remaining cell lines.

On the basis of the FISH result (before obtaining the karyotype), the ultrasound findings and counselling of sequalae, the couple decided to undergo a medical termination of pregnancy. Cordocentesis was not performed because the couple declined further invasive testing. Fetocide, which allows cardiac blood sampling, was not considered because, in 
compliance with the Royal College of Obstetricians and Gynaecologists guidance, the unit does not perform this invasive procedure unless the gestation of the fetus at the time of termination is greater than 21 weeks and 6 days.'

At delivery macroscopic examination showed a female infant with rockerbottom feet, talipes equinovarus, syndactyly, saddle nose, wide first web toe, micrognathia and low set ears. Postmortem examination in addition to the above revealed only cerebral ventriculomegaly. Unfortunately no cytogenetics was obtained from fetal tissue but cytogenetic analysis of chorion revealed a 69, XXX pattern.

\section{QUESTIONS}

(1) What is the prognosis and management of mild cerebral ventriculomegaly?

(2) What are the causes of two cell lines in a sample of amniotic fluid after amniocentesis?

(3) What is the "best guess" diagnosis?

Postgrad Med J 2003;79:478-479

\section{REFERENCE}

1 Royal College of Obstetricians and

Gynaecologists. Further issues relating to late abortion, fetal viability and registration of births and deaths. London: RCOG, April 2001 (http://www.rcog.org.uk).

\section{Authors' affiliations}

M Cameron, Scottish Programme for Clinical Effectiveness in Reproductive Health G Cumming, P Smith, Department of Obstetrics and Gynaecology, Aberdeen Maternity Hospital, Aberdeen

Correspondence to: Dr Martin Cameron, University Department of Obstetrics and Gynaecology, Clinical Research Room, Top Floor, Aberdeen Maternity Hospital, Cornhill Road, Aberdeen AB25 2ZD, UK

m.j.cameron@abdn.ac.uk

Submitted 8 November 2002

Accepted 30 January 2003

\section{A young woman with palpitations}

(3) Is this patient at risk for sudden death? If yes, how will you evaluate her for this risk?

Postgrad Med J 2003;79:479

\section{A A Khasnis, S C Kantipudi, R K Thakur}

\section{Answers on p 483.}

$\Lambda$ 0 year old woman presented with paroxysmal episodes of palpitations that she had had for two years. Initially the episodes occurred 3-6 months apart but they had become more frequent before presentation. Occasionally, the episodes were associated with pre-syncope. She described her palpitations as regular and rapid. She had no other past significant medical history. Examination of the cardiovascular system was normal. She had no clinical evidence of hyperthyroidism or thyroid enlargement. All laboratory investigations were normal. Her electrocardiogram (ECG) taken at rest is shown in fig 1 .

\section{QUESTIONS}

(1) What does the ECG show?

(2) What should be the next step in management?

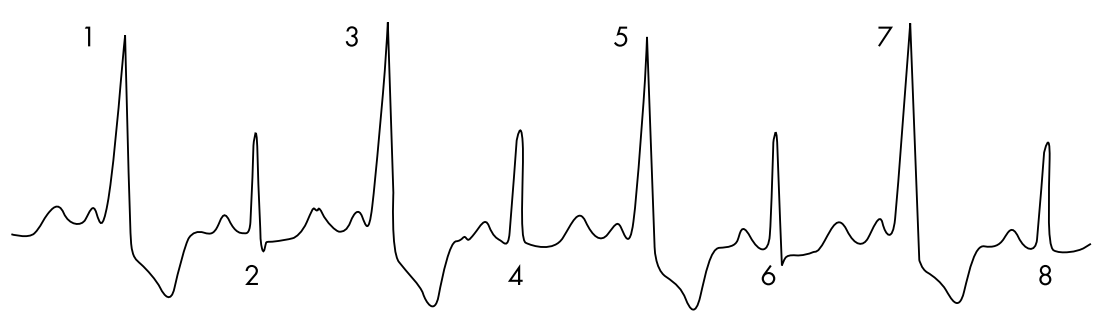

Figure 1 ECG at rest. 